\title{
AC 2012-3927: ASSESSING AN ADAPTIVE EXPERTISE INSTRUMENT IN COMPUTER-AIDED DESIGN (CAD) COURSES AT TWO CAMPUSES
}

\section{Dr. Michael Johnson, Texas A\&M University}

Michael D. Johnson is an Assistant Professor in the Department of Engineering Technology and Industrial Distribution at Texas A\&M University. Prior to joining the faculty at Texas A\&M, he was a senior product development engineer at the 3M Corporate Research Laboratory in St. Paul, Minn. He received his B.S. in mechanical engineering from Michigan State University and his M.S. and Ph.D. from the Massachusetts Institute of Technology. Johnson's research focuses on design tools; specifically, the cost modeling and analysis of product development and manufacturing systems; computer-aided design methodology; and engineering education. His work has been published in the International Journal of Production Economics, IEEE Transactions on Engineering Management, and the Journal of Engineering Design.

Mrs. Elif Ozturk, Texas A\&M University

Joshua Johnson, Prairie View A\&M University

Teaching Assistant

\section{Dr. Bugrahan Yalvac, Texas A\&M University}

Bugrahan Yalvac is an Assistant Professor of science education in the Department of Teaching, Learning, and Culture at Texas A\&M University, College Station. He received his Ph.D. in science education at the Pennsylvania State University in 2005. Prior to his current position, he worked as a learning scientist for the VaNTH Engineering Research Center at Northwestern University for three years. Yalvac's research is in STEM education, 21st century skills, and design and evaluation of learning environments informed by the How People Learn framework.

\section{Dr. Xiaobo Peng, Prairie View A\&M University}

Xiaobo Peng is an Associate Professor in the Department of Mechanical Engineering at Prairie View A\&M University. 


\title{
Assessing an Adaptive Expertise Instrument in Computer-aided Design (CAD) Courses at Two Campuses
}

\begin{abstract}
In today's highly competitive market, CAD tools are widely used and thought to reduce time to market and increase engineering productivity. However, to take advantage of these putative benefits requires proper use of CAD tools. Merely teaching declarative knowledge (particular keystrokes and button picks) in CAD is not sufficient; students should acquire deeper procedural knowledge (design strategy) in CAD. This will allow them to gain a level of expertise that is adaptive in nature. Recent research in engineering education finds that experts demonstrate two distinct characteristics: adaptive versus routine expertise. Adaptive experts possess the content knowledge similar to routine experts in the field, but also the ability to effectively utilize and extend their content knowledge. Epistemological beliefs, metacognitive skills, multiple perspectives, and learning orientations are among the constructs that can define adaptive expertise.

This work describes the implementation of an instrument used to measure adaptive expertise in two courses at two universities. The instrument contains questions covering four dimensions: multiple perspectives, meta-cognitive self-assessment, goals and beliefs, and epistemology. In one university setting, freshmen and sophomore engineering students were surveyed with the instrument; in the other, junior and senior level engineering students were surveyed. In addition to the student participants, practicing engineers from industry were surveyed using the instrument. Participant demographic, education, and engineering experience data were collected. These data were used to examine the relationships among expertise related responses and demographic variables. We report the factor analyses results and the reliability coefficients of the instrument and the observed differences between students' and engineers' responses to survey items.
\end{abstract}

\section{Introduction}

Computer-aided design (CAD) tools are ubiquitous and used throughout the development process in many industries ${ }^{1}$. CAD tools are available in multiple platforms and change quickly. This makes it imperative that students are trained in a manner that allows them to adapt and transfer their accrued skills to new platforms and versions of these CAD tools. Unfortunately, most instruction related to $\mathrm{CAD}$ is focused on declarative knowledge: that which is related to the specific steps required to perform certain tasks in particular CAD platforms ${ }^{2,3}$. This is opposed to the strategic knowledge that is associated with CAD expertise ${ }^{4}$. This strategic knowledge entails the planning of CAD models and the communication of design intent ${ }^{2,4-6}$. This strategic knowledge should be adaptable to other CAD 
program versions and platforms; it should represent expertise that is adaptive. Lang et al., note the transferability of CAD expertise based on procedural knowledge ${ }^{4}$.

This work represents the first step in a project to examine the adaptive nature of CAD expertise and its role on modeling behavior. This work assessed an adaptive expertise instrument that has been used to capture the adaptive expertise of students at two universities as well as several practicing engineers. Later the instrument will be used to relate general adaptive expertise to CAD-specific adaptive expertise and modeling procedure. The overall goal is to examine how to better train students and improve the adaptive nature of their CAD expertise.

\section{Routine versus Adaptive Expertise}

Expertise is the ability to complete the domain specific tasks effectively and quickly ${ }^{7}$. Chi describes what is known as the relative approach: comparing experts to relative novices ${ }^{8}$. Experts have been found to be better at processing information ${ }^{9}$; and to spend more time on data gathering and problem solving ${ }^{10}$. In a design specific context, experts are shown to take a more "sophisticated" approach to solving a problem ${ }^{11}$. Experts are also more likely to use abstract solutions and analogies than novices ${ }^{12}$; produce more cognitive actions and have a more top down structural organization ${ }^{13}$. Little work has been done looking specifically at expertise in CAD. Two early studies noted the transferability (or adaptive nature) of procedural knowledge ${ }^{4,14}$. Expert modelers have been examined to determine if there held a "common modeling procedure" ${ }^{15}$. One study found that expert instruction could cause students to adopt a significant number of expert modeling strategies 5 .

Typically when assessing student competence and expertise, the criteria focus on specific task and problems; rarely do we evaluate students' metacognitive skills or their epistemological positions regarding the subject matter they are learning. However, these are the cognitive skills that are critical for effective use of modern CAD programs ${ }^{5,16}$. There is a need to make the engineering curriculum less instructor focused ${ }^{17}$ and allow for development of self-regulation and metacognitive skills, and more self-learning and monitoring ${ }^{18}$.

When experts have to perform specific tasks (e.g., solving a problem in that new domain) and encounter unstructured or novel problems in their domain or come into contact with a new context, they are required to generate new knowledge and ideas that are useful for achieving an innovative and appropriate outcome. Experts should be able to inquire effectively and use their self-regulating skills to identify and comprehend a problem, to identify what additional knowledge is necessary, and to generate ideas and leverage existing knowledge to facilitate awareness of relevant information. Appropriately generating new knowledge requires skills to be innovative where quickly and accurately applying the already known knowledge requires skills to be efficient ${ }^{19}$.

Hatano and Inagaki characterized two kinds of expertise: routine and adaptive ${ }^{20}$. Adaptive experts are able to innovate and be efficient in their domain, where routine experts are only efficient. Schwartz, et al., defined the trajectory of adaptive expertise as a balance between efficiency and innovation. They proposed that innovation and efficiency should be developed together and learning experiences should 
promote these two dimensions to grow and develop simultaneously ${ }^{21}$. Adaptive experts possess the subject specific knowledge and technical proficiency similar to that of routine experts. In contrast to routine experts, adaptive experts inquire for new learning in their domain expertise, successfully monitor their understanding and thinking, and conceive of knowledge as dynamic rather than static ${ }^{21}$. In other words, adaptive experts tend to be more open to inquire, to use their metacognitive and selfregulation skills, and to hold more advanced personal epistemologies. These characteristics make the adaptive experts flexible, innovative, and creative particularly in novel situations ${ }^{22}$. Ability to evaluate one's own knowledge domain and identifying the knowledge needed to be added so as to solve the given task is attributed to metacognitive thinking skill. Personal epistemology is defined as one's beliefs on and attitudes towards the nature of the knowledge in the field and its generation. Adaptive experts often hold more sophisticated personal epistemologies than those of routine experts. That is, adaptive experts believe the knowledge in their field is dynamic in nature and it is subject to change as needed. The belief that the domain knowledge is not static and fixed, yet it is dynamic and subject to change enables the adaptive experts to be more flexible and welcoming to adapt new ways to inquire or generate knowledge to immediately apply in novel platforms. Identifying adaptive experts and assessing the adaptive nature of their CAD expertise will inform and allow for the improvement of CAD education.

\section{Study Purpose}

This work tested an instrument developed by Fisher and Peterson that was used to assess the adaptive expertise of Biomedical Engineering students ${ }^{23}$ on three distinct populations: freshman undergraduate students, junior level undergraduate students, and practicing engineers from a Fortune 100 company. The effects of various demographic and experience related characteristics on adaptive expertise are examined. The remainder of the paper is organized as follows. The next section details the methods used to gather and analyze data using the instrument. The following section details the results of the survey and analysis. Finally, results are discussed and conclusions and limitations are presented.

\section{Methods}

To test the validity and reliability of the adaptive expertise instrument, we administered it to 64 students at two university campuses and to six engineers in industry. The survey our participants completed included a demographic questionnaire and the 42 items, 6-point Adaptive Expertise Likert$\mathrm{scale}^{23}$. Three parallel forms were designed for the two campuses and for the industry participants. A sample student form including demographic questions and adaptive expertise survey items is included in the Appendix.

\section{Data Collection}

The student data were collected during a class session in CAD courses taught by two of the authors. One of the researchers who is not the course instructor attended the class meetings at the two campuses, explained the purpose of the survey administration to the students in class, and administered the IRB approved human consent forms. Students were informed that their responses 
were confidential and they would not be shared with their course instructors until final course grades were submitted. Students who agreed to participate signed the consent forms and then completed the surveys. Industry participants were recruited via email; that they were asked to review the e-copy of the IRB approved consent form and provide their consent by signing the form if they agreed to participate. The consent forms and the completed surveys were collected by one of our researchers via email. We organized the demographic questionnaire and survey data in an excel sheet and analyzed them on both SPSS and JMP statistical software.

\section{Analyses}

In our analyses, we first explored the validity and the reliability of the adaptive expertise Likert-scale with the data we collected from the students and the engineers. Next, we explored the observable differences between the participants' demographics and their responses to the survey items. The number of participants who completed the surveys and their demographic information are summarized in Table 1.

Table 1. Number of participants and their demographics.

\begin{tabular}{|c|c|c|c|c|c|c|c|c|c|c|c|c|c|c|c|c|c|c|}
\hline & \multirow[b]{2}{*}{$\mathrm{N}$} & \multicolumn{2}{|c|}{ Sex } & \multicolumn{3}{|c|}{ Age } & \multicolumn{2}{|c|}{ Major } & \multicolumn{4}{|c|}{$\begin{array}{l}\text { Work exp. Technical or } \\
\text { related to eng. research exp. }\end{array}$} & \multicolumn{2}{|c|}{$\begin{array}{c}\text { First } \\
\text { generation }\end{array}$} & \multicolumn{4}{|c|}{ Rank } \\
\hline & & Male & Female & $18-22$ & $23-30$ & $>30$ & MechEng & Other & Yes & No & Yes & No & Yes & No & Fresh & Soph & Junior & Senior \\
\hline $\begin{array}{l}\text { Students at } \\
\text { Campus } 1\end{array}$ & 32 & 30 & 2 & 22 & 9 & 1 & 31 & 0 & 13 & 19 & 18 & $14 ?$ & NA & NA & 0 & 0 & 2 & 30 \\
\hline $\begin{array}{l}\text { Students at } \\
\text { Campus } 2\end{array}$ & 32 & 26 & 6 & 30 & 0 & 2 & 29 & 1 & 0 & 32 & 4 & 28 & 20 & 12 & 24 & 6 & 1 & 1 \\
\hline & & & & & & & \multicolumn{2}{|c|}{ Highest degree } & \multicolumn{4}{|c|}{ Years in service } & & & & & & \\
\hline & & & & & & & $\mathrm{BS}$ & Other & $<5$ & $>5$ & $<10=$ & $=>10$ & & & & & & \\
\hline $\begin{array}{c}\text { Practitioner } \\
\text { engineers }\end{array}$ & 6 & 6 & 0 & 0 & 0 & 6 & 6 & 0 & 1 & 2 & & 3 & & & & & & \\
\hline Total: & 70 & 62 & 8 & 52 & 9 & 9 & & & & & & & To & tal: & 24 & 6 & 3 & 31 \\
\hline
\end{tabular}

\section{Explorative Factor Analysis}

To explore the possible dimensions that the adaptive expertise survey measures, we utilized Explorative Factor Analysis (EFA) with the data collected from the students and the industry participants. When we used the principle components analysis for the Likert-scale data, we observed 14 factors with eigen values greater than 1 ; these represented $73.4 \%$ of the total variances in the response pattern (Table 2). The eigenvalue of a factor represents the factor's variation in relation to the total variations in the sample. 
Table 2. Factors with eigen values more than 1 representing 73.4 percent of the response pattern.

\begin{tabular}{|c|c|c|c|c|c|c|c|}
\hline actors & Eigenvalue & Percent & Percent & Cum Percen & ChiSquare & DF & Prob $>$ ChiSq \\
\hline 1 & 5.7631 & 13.722 & $\square$ & 13.722 & 1836.59 & 902.000 & $<.0001^{*}$ \\
\hline 2 & 3.6780 & 8.757 & $\square$ & 22.479 & 1608.08 & 860.000 & $<.0001^{*}$ \\
\hline 3 & 2.8361 & 6.753 & 世 & 29.232 & 1479.22 & 819.000 & $<.0001^{*}$ \\
\hline 4 & 2.4784 & 5.901 & ㄸ & 35.133 & 1388.23 & 779.000 & $<.0001^{*}$ \\
\hline 5 & 2.3272 & 5.541 & ㄸ & 40.674 & 1309.41 & 740.000 & $<.0001^{*}$ \\
\hline 6 & 2.0031 & 4.769 & $\square$ & 45.443 & 1230.78 & 702.000 & $<.0001^{*}$ \\
\hline 7 & 1.8233 & 4.341 & ם & 49.784 & 1165.88 & 665.000 & $<.0001^{*}$ \\
\hline 8 & 1.7408 & 4.145 & ㅁ & 53.929 & 1106.29 & 629.000 & $<.0001^{*}$ \\
\hline 9 & 1.6490 & 3.926 & ㅁ & 57.855 & 1045.40 & 594.000 & $<.0001^{*}$ \\
\hline 10 & 1.5373 & 3.660 & $\square$ & 61.515 & 983.958 & 560.000 & $<.0001 *$ \\
\hline 11 & 1.4289 & 3.402 & $\square$ & 64.917 & 923.947 & 527.000 & $<.0001 *$ \\
\hline 12 & 1.3055 & 3.108 & & 68.026 & 865.629 & 495.000 & $<.0001^{*}$ \\
\hline 13 & 1.1898 & 2.833 & $\square$ & 70.859 & 811.175 & 464.000 & $<.0001^{*}$ \\
\hline 14 & 1.0977 & 2.614 & 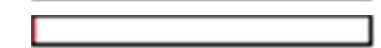 & 73.472 & 760.822 & 434.000 & $<.0001^{*}$ \\
\hline
\end{tabular}

*Indicates that the difference is significantly meaningful.

The two commonly used tests for deciding the number of factors to retain are the eigen value rule ${ }^{24}$ and the scree test ${ }^{25}$. Eigen value rule recommends retaining the factors with eigen values of at least one. Scree test recommends retaining factors above a break point on a scree plot. In other words, the factors above a point in the plot indicating a strong linear descending trend in the remaining eigenvalues are retained. The scree plot generated with the data collected indicated multiple break points (Figure 1), e.g., after the $4^{\text {th }}, 7^{\text {th }}, 14^{\text {th }}, 17^{\text {th }}$, and $21^{\text {st }}$ eigenvalues. $14^{\text {th }}$ factor is the last factor with an eigen value above 1, and it represents a break point in the scree plot. Relying on the eigen value rule and scree test, we assumed that the survey might have 14 factors.

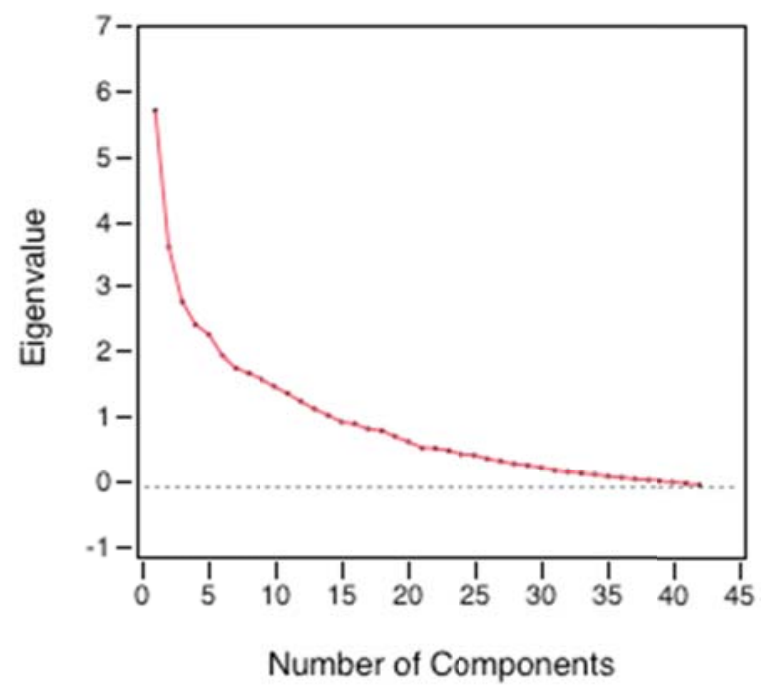

Figure 1. The Scree plot for the explorative factor analysis. A break point appears to be on the $14^{\text {th }}$ factor where the eigenvalue is slightly more than 1.0. 
When we used the common factor analysis with 14 factors and applied the maximum likelihood and the varimax rotations ${ }^{26}$, the model-fit statistics computed a reasonable chi-square value $\left(\chi^{2}=410,807\right.$, $\mathrm{p}=0.0455)$. The model-fit statistics, presented in Table 3, still suggest the possibility of more factors, however when we assessed the same analysis with 15 or more factors, the system did not converge. This led to the conclusion that the most meaningful factor loading was 14 regardless of the rejection of the null hypothesis in the model-fit analysis (Test 2). These results are shown in Table 3. The first test examines if at least one common factor exists. This criterion is validated. Second test examines if 14 factors are sufficient to explain the survey sub-dimensions. This criterion is not validated.

Table 3. The fit statistics (significant tests) with 14 factors loaded.

\begin{tabular}{lrrr}
\hline Test 1 & $\mathrm{DF}$ & ChiSquare & Prob $>$ ChiSq \\
$\mathrm{H}_{\mathrm{o}}:$ no common factors. & 861.000 & 1441.770 & $<.0001^{*}$ \\
$\mathrm{H}_{\mathrm{A}}:$ at least one common factor. & & & \\
Test 2 & $\mathrm{DF}$ & ChiSquare & Prob $>$ ChiSq \\
$\mathrm{H}_{\mathrm{o}}: 14$ factors are sufficient. & 364.000 & 410.807 & $0.0455^{*}$ \\
$\mathrm{H}_{\mathrm{A}}:$ more factors are needed. & & & \\
\hline
\end{tabular}

*Statistically significant differences suggest that null hypothesis $\left(\mathrm{H}_{\mathrm{o}}\right)$ is rejected.

When we used 14 factors, the cumulative percentage of the variances explained by these 14 items was computed as $52.3 \%$. In the EFA without the 14 factors were set and the varimax rotation was computed, the first 14 factors had accounted for $49.7 \%$ of the total variance $(100 \%)$ in the data (see Table 2).

Table 4. Variances explained by each factor when 14 factors are loaded.

\begin{tabular}{cccc}
\hline Factor & Variance & Percent & Cum Percent \\
Factor 1 & 3.0578 & 7.280 & 7.280 \\
Factor 2 & 2.0629 & 4.912 & 12.192 \\
Factor 3 & 2.0209 & 4.812 & 17.004 \\
Factor 4 & 1.9708 & 4.692 & 21.696 \\
Factor 5 & 1.9224 & 4.577 & 26.273 \\
Factor 6 & 1.7488 & 4.164 & 30.437 \\
Factor 7 & 1.7182 & 4.091 & 34.528 \\
Factor 8 & 1.6324 & 3.887 & 38.415 \\
Factor 9 & 1.5698 & 3.738 & 42.152 \\
Factor 10 & 1.5550 & 3.702 & 45.855 \\
Factor 11 & 1.2937 & 3.080 & 48.935 \\
Factor 12 & 0.7983 & 1.901 & 50.836 \\
Factor 13 & 0.5687 & 1.354 & 52.190 \\
Factor 14 & 0.0476 & 0.113 & 52.303 \\
\hline
\end{tabular}


As mentioned above, our study has 70 participants; that is less than the desired number of subjects to compute meaningful factor analysis ${ }^{27,28}$. The low number of participants might have limited the factor loadings to fit with the model.

\section{Confirmative Factor Analysis}

It is obvious that the adaptive expertise survey was not intended to generate 14 factors. In the Confirmative Factor Analysis (CFA), we assumed that the survey has 4 factors as highlighted by

Fisher and Peterson ${ }^{23}$. Moreover, in the scree plot of the EFA (see Figure 1), the $5^{\text {th }}$ factor indicated a break point that promotes the likelihood of four factors. The total variance explained by the four factors computed to $28.83 \%$. The variance of each factor and the cumulative percentage of the variances are given in Table 5. Table 6 lists the 42 survey items and the factors they are grouped into.

Table 5. Variances explained when the factor number is set to 4.

\begin{tabular}{lccc}
\hline Factor & Variance & Percent & Cum Percent \\
Factor 1 & 3.4009 & 8.097 & 8.097 \\
Factor 2 & 3.3736 & 8.032 & 16.130 \\
Factor 3 & 2.8130 & 6.698 & 22.827 \\
Factor 4 & 2.5190 & 5.998 & 28.825 \\
\hline
\end{tabular}


Table 6. Factors loaded.

\begin{tabular}{|c|c|c|c|c|}
\hline Item & Factor 1 & Factor 2 & Factor 3 & Factor 4 \\
\hline q42 & 0.660209 & 0.082651 & 0.346686 & 0.322946 \\
\hline q37 & 0.607785 & 0.007839 & 0.019421 & 0.3094 \\
\hline q5 & 0.54535 & -0.023518 & 0.160887 & -0.004551 \\
\hline q $22 *$ & 0.482721 & $0.43082 *$ & 0.032788 & 0.063962 \\
\hline q36 & 0.452791 & -0.034831 & 0.14462 & 0.065658 \\
\hline q34 & 0.429321 & -0.098975 & 0.113866 & 0.006212 \\
\hline q20 & 0.340461 & 0.31873 & 0.312111 & 0.109926 \\
\hline$q 25$ & 0.33005 & 0.193776 & 0.031901 & -0.208895 \\
\hline q38 & 0.325867 & 0.231728 & 0.219625 & 0.036153 \\
\hline q16 & 0.290293 & -0.041451 & -0.031023 & -0.028221 \\
\hline $\mathrm{q} 28$ & -0.541586 & 0.072774 & 0.522285 & 0.290773 \\
\hline q14 & 0.143225 & 0.731793 & 0.146989 & -0.251036 \\
\hline q10 & 0.320888 & 0.65244 & 0.034766 & 0.202743 \\
\hline q26 & -0.01506 & 0.549612 & -0.344418 & 0.07055 \\
\hline q6 & -0.268641 & 0.535739 & 0.240775 & 0.262493 \\
\hline $\mathrm{q} 18^{*}$ & -0.050046 & 0.48318 & -0.047642 & $0.472003 *$ \\
\hline $\mathrm{q} 40^{*}$ & $0.433947 *$ & 0.467805 & 0.151336 & 0.046926 \\
\hline q30 & 0.064071 & 0.450919 & 0.053266 & 0.192377 \\
\hline q33 & -0.119522 & 0.294232 & -0.041969 & 0.202212 \\
\hline q15 & -0.120738 & 0.255825 & 0.194221 & 0.11222 \\
\hline $\mathrm{q} 2$ & -0.148049 & 0.254013 & 0.13872 & 0.077225 \\
\hline q3 & 0.174682 & -0.309718 & 0.031031 & 0.211876 \\
\hline$q 23$ & 0.056237 & 0.040637 & 0.619682 & -0.275815 \\
\hline q8 & 0.185206 & 0.37087 & 0.477701 & 0.16643 \\
\hline $\mathrm{q} 21$ & 0.23385 & 0.034064 & 0.438789 & -0.164306 \\
\hline q39 & 0.405501 & -0.01197 & 0.412288 & 0.147084 \\
\hline q27 & 0.030895 & -0.212593 & 0.397152 & -0.112352 \\
\hline q7 & 0.168064 & 0.070507 & 0.373566 & 0.199828 \\
\hline q19 & -0.324312 & 0.239821 & 0.332568 & 0.069643 \\
\hline q9 & 0.062931 & 0.085401 & 0.320242 & 0.27177 \\
\hline q11 & 0.055198 & 0.1389 & 0.264674 & 0.098666 \\
\hline q13 & 0.077159 & -0.012282 & 0.199918 & -0.035445 \\
\hline $\mathrm{q} 41$ & 0.048159 & 0.045589 & 0.156443 & 0.105584 \\
\hline$q 35$ & 0.133454 & -0.067874 & -0.18916 & 0.044741 \\
\hline q31 & -0.047202 & 0.029928 & -0.498182 & 0.109437 \\
\hline q32 & 0.049548 & 0.078042 & 0.030793 & 0.665363 \\
\hline q12 & -0.078025 & 0.289673 & 0.037617 & 0.529714 \\
\hline q24 & -0.091773 & 0.266938 & 0.105627 & 0.479967 \\
\hline $\mathrm{q} 4$ & 0.220063 & 0.080989 & 0.039815 & 0.350862 \\
\hline q17 & -0.012513 & -0.020976 & 0.010463 & 0.336959 \\
\hline q1 & 0.047304 & 0.003132 & -0.057377 & 0.2864 \\
\hline q29 & 0.033415 & 0.022395 & -0.044322 & 0.17795 \\
\hline
\end{tabular}

*Indicates that items can load on one or more factors. 
Fisher and Peterson listed the four dimensions of their scale as, "multiple perspectives," "metacognitive self-assessment," "goals and beliefs," and "epistemology"23. Table 7 lists the items Fisher and Peterson grouped under each sub-dimension and the items that are grouped in our CFA. For the item verbiage, please refer to the Appendix.

Table 7. Items that were originally grouped by Fisher and Peterson (2001) and items that were grouped by the CFA.

\begin{tabular}{|c|c|c|c|}
\hline Multiple perspectives & $\begin{array}{l}\text { Metacognitive self- } \\
\text { assessment }\end{array}$ & Goals and beliefs & nology \\
\hline $\begin{array}{l}1,17,29,5,9,13 \\
21,25,34,36,39 .\end{array}$ & $\begin{array}{l}2,6,10,14,18,26,30, \\
40,22 .\end{array}$ & $\begin{array}{l}7,11,19,23,27,31,35 \\
41,3,15,24,32,38\end{array}$ & $\begin{array}{l}16,20,28,37,42,4, \\
8,12,33 .\end{array}$ \\
\hline $\begin{array}{l}\mathbf{1}, \mathbf{1 7}, \mathbf{2 9}, 4,12,24, \\
32 . \\
\text { (Factor } 4)\end{array}$ & $\begin{array}{l}2,6,10,14,18,26,30, \\
40,3,15,33, \\
\text { (Factor } 2)\end{array}$ & $\begin{array}{l}7,11,19,23,27,31,35 \\
41,8,9,13,21,39 . \\
\text { (Factor } 3 \text { ) }\end{array}$ & $\begin{array}{l}16,20,28,37,42,5, \\
22,25,34,36,38 . \\
\text { (Factor } 1)\end{array}$ \\
\hline
\end{tabular}

Italic and bolded items grouped similarly.

The "metacognitive self-assessment" dimension has the most matching items. Only one item, question 22, loaded with the "epistemology" dimension in our CFA. However, the factor loading of this item for the second factor ("metacognitive self-assessment" dimension) is sufficiently high to be included in the "metacognitive self-assessment" dimension (0.43082, as indicated in Table 6, line 5, column 3). This concludes that the factor 2 items grouped in our CFA effectively represent the "metacognitive self-assessment" dimension that Fisher and Peterson reported.

The second most matching items grouped in our CFA were in the "goals and beliefs" dimension. Eight out of 13 items were grouped in factor number 3. In the third factor we computed, only four out of 12 items did not match with the items in the "goals and beliefs" dimension Fisher and Pederson noted ${ }^{23}$. Five items in "epistemology" dimension matched with the factor 1 items that were computed. In the multiple perspectives dimension, only three out of 11 items were matched. This suggests that "multiple perspectives" dimension is the least reliable dimension and the survey items belonging to this dimension interact with the other dimensions the most. If any items ought to be excluded for the next administrations, items from the "multiple perspectives" are the first ones to be considered.

\section{Reliability of the Scale}

The reliability of the scale is computed with Cronbach's alphas. The Cronbach's alpha values for each sub-dimension and for all survey items are given in Table 8. The Cronbah's alpha of the survey is computed $0.79(\mathrm{~N}=70)$, which indicates that the survey is a reliable instrument. "Goals and beliefs" dimension has the lowest reliability coefficient $(\alpha=0.39)$ where the "metacognitive self-assessment" dimension has the highest reliability coefficient $(\alpha=0.77)$. 
Table 8. Cronbach's $\alpha$ values for each sub-dimension and all items.

\begin{tabular}{cccccc}
\hline & $\begin{array}{c}\text { Multiple } \\
\text { Perspectives }\end{array}$ & $\begin{array}{c}\text { Metacognitive } \\
\text { Self-Assessment }\end{array}$ & $\begin{array}{c}\text { Goals \& } \\
\text { Beliefs }\end{array}$ & Epistemology & All items \\
\hline Cronbach's $\alpha$ & 0.5116 & 0.7785 & 0.3963 & 0.6200 & 0.7924 \\
\hline Means & 3.9527 & 3.9043 & 4.1581 & 4.2267 & 4.0604 \\
\hline SDs & 0.4962 & 0.4037 & 0.6715 & 0.5778 & 0.3847 \\
\hline
\end{tabular}

It is not surprising that "meta-cognitive self-assessment" dimension has the highest cronbach's alpha value among the other three sub-dimensions because almost all item in "meta-cognitive selfassessment" dimensions were loaded on one factor as abovementioned.

The EFA and the CFA recommend that the survey overall is a reliable instrument and the factors are reasonably loaded under four sub-dimensions. To improve the survey items, one may consider modifying or excluding the items that did not matched in the four factor loaded CFA.

\section{Relations between the Survey Dimensions and Participants' Characteristics}

To examine the relationships between the sub-dimensions of the scale and participants' characteristics (e.g., sex, age, years of experience, major, etc.), we used both parametric and non-parametric tests. Because the group sizes of the two campus locations were exactly the same (i.e., 32), a parametric test was sufficient to compare the location differences between the two campuses. However, due to the small sample size of industry participants $(N=6)$, compared to the students $(N=64)$, non-parametric tests were used. Non-parametric tests were also used for female students $(N=6)$, juniors-level students $(N=3)$ and sophomore-level students $(N=6)$ as compared to their more numerous counterparts: male students $(\mathrm{N}=60)$, freshmen $(N=24)$, and seniors $(N=31)$. In these cases, we utilized both parametric and non-parametric tests to examine the effect of the dependent variable. Here we only report the statistically significant differences observed in parametric and/or non-parametric tests.

When we compared the students' $(N=64)$ and practicing engineers' $(N=6)$ responses to the adaptive expertise 6-point Likert-scale items, the non-parametric tests using the Wilcoxon method revealed significant differences in "metacognitive self-assessment" dimension, $\left(M_{s}=4.19, S D_{s}=0.08 ; M_{e}=3.72\right.$, $\left.S D_{e}=0.11 ; Z=-2.19, p<0.05\right)$ in the "epistemology" dimension, $\left(M_{\mathrm{s}}=4.28, S D_{s}=0.55, M_{e}=3.55\right.$, $\left.S D_{e}=0.39, Z=-3.00, p<0.01\right)$ and in overall survey scores $\left(M_{s}=4.09, S D_{s}=0.38, M_{e}=3.69, S D_{e}=0.12, Z=\right.$ $-2.77, p<0.01)$. For "multiple perspectives" and "goals and beliefs" dimensions, the non-parametric comparisons revealed no difference $(p>0.05)$.

The non-parametric tests for gender differences $\left(N_{\text {males }}=62, N_{\text {females }}=8\right)$ revealed no statistically significant difference among the four sub-dimensions and for the overall survey scores. Both parametric and non-parametric test results revealed no differences between the first generation college attendee students $(N=20)$ and not first generation students $(N=12)$.

When the scores of the students with professional work experience related to engineering $(N=13)$ and students without any previous professional work experience $(N=51)$ were compared, we found 
statistically significant differences in "multiple perspectives" dimension $\left(M_{\mathrm{wexp}}=4.23, S D_{\mathrm{wexp}}=0.55\right.$; $\left.M_{\text {woutexp }}=3.91, S D_{\text {wexp }}=0.48 ; Z=2.02, p<0.05\right)$ and in all survey items $\left(M_{\text {wexp }}=4.27, S D_{\text {wexp }}=0.40\right.$; $\left.M_{\text {woutexp }}=4.04, S D_{\text {wexp }}=0.36 ; Z=2.03, p<0.05\right)$ as revealed from the non-parametric tests using Wilcoxon method. When the parametric independent-t tests were used to analyze the same scores, "multiple perspectives" revealed significant difference $\left(t(62)=2.03, p=0.046^{*}\right)$ but the overall survey items revealed no significant difference $(t(62)=1.89, p=0.063)$ when $\mathrm{p}^{*}$ value less than 0.05 is used.

When we compared the students who had technical work or research experience $(N=22)$ and the students who did not have any technical work or research experience $(N=42)$, their mean scores for the four sub-dimensions and for all items revealed no significant difference in both parametric and nonparametric tests.

When we compared the students' scores across the two campuses ( $\left.N_{\text {campus } 1}=32, N_{\text {campus } 2}=32\right)$, in “epistemology" dimension $\left(M_{\text {campus } 1}=4.49, S D_{\text {campus } 1}=0.09, M_{\text {campus } 2}=4.08, S D_{\text {campus } 2}=0.09, \mathrm{t}(62)=-3.09\right.$, $\mathrm{p}<0.00)$ and in overall items in the survey $\left(M_{\text {campus } 1}=4.19, S D_{\text {campus }}=0.41, M_{\text {campus } 2}=3.99\right.$, $\left.S D_{\text {campus } 2}=0.32, \mathrm{t}(62)=-2.15, \mathrm{p}=0.03^{*}\right)$ we found statistically significant differences when $\mathrm{p}$ value less than 0.05 is used. In other three sub-dimensions, no difference was observed.

When we compared the students' ranks (i.e., freshman, sophomore, junior, and senior) and their scores of the survey items, we found a statistically significant difference in "epistemology" sub-dimension. Analysis of variance showed a main effect of students' rank on epistemology item scores ( $F(3$, $60)=3.97, p=0.01)$. Post-hoc analysis using Tukey-Kramer's HSD indicated that seniors' $(N=31)$ epistemology item scores $\left(M_{\mathrm{sen}}=4.48, S D_{\mathrm{sen}}=0.60\right)$ were significantly higher than freshmen's $(N=24)$ epistemology item scores $\left(M_{\text {fresh }}=4.03, S D_{\text {fresh }}=0.41\right)(p=0.01)$. Because the sample sizes were considerably un-equal (i.e., freshmen 31 , sophomore 6 , junior 3 , and seniors 31 ), we also run nonparametric Wilcoxon test to examine the rank differences. The comparisons of each pair using Wilcoxon method revealed differences between seniors and freshmen in epistemology scores $(Z=2.96$, $p<0.00)$ and between juniors $\left(M_{\text {juniors }}=4.49, S D_{\text {juniors }}=0.12\right)$ and freshmen $\left(Z=2.44, p=0.01^{*}\right)$. For all items, non-parametric tests revealed a difference between seniors and freshmen $\left(Z=2.46, p=0.01^{*}\right)$ but a parametric test (ANOVA) did not $(\mathrm{F}(3,60)=1.79, \mathrm{p}=0.15)$ when $\mathrm{p}$ value less than 0.05 is used. It should be noted that the rank and campus location results significantly overlap as the course at Campus 1 was exclusively juniors and seniors and that at Campus 2 was mainly freshmen and sophomores.

\section{Discussion}

The instrument we tested in this study was found sufficiently reliable with a cronbach's alpha of 0.7924 . The 4 factor loading variances explained 29 percent of the overall variances in the response pattern. Even though the represented variance percent of the response pattern is less than the desired value (e.g., $>50$ percent), the loadings of the items represented the theoretical item pattern quite effectively. One reason for the low variance representation is because the total number of participants is significantly less than the desired sample size for factor analysis. We had 70 participants and the 
survey had 42 questions. This is less than 2:1 ratio. It is recommended that the number of participants for factor analysis would be at least 100 or five times the number of items in the scale (5:1 ratio). In the next survey administrations, more data will be collected from students and engineers and the data pool will increase.

The industry participants' response pattern was different from the students' responses in epistemology, metacognitive self-assessment, and in overall survey responses. This finding suggests that students have more adaptive expertise characteristics than the engineers which conflicts with our theoretical assumption. When students' responses were examined among themselves, the senior students' metacognition and self-assessment scores were significantly higher than freshman students'. This finding suggests that students' meta-cognitive self-assessment skills improve as they advance in their program of studies. Additional data from engineers may result in different conclusions.

\section{Conclusions}

The purpose of this work was to test an adaptive expertise Likert-scale developed by Fisher and Peterson $^{23}$. Sixty-four students and six practicing engineers completed the survey. The Cronbach's alpha values and the four factor loadings showed a reliable and a sufficiently valid Likert-scale. We plan using the instrument in our next data collection effort. The data collected from the engineers revealed somewhat conflicting results. This is likely because of the very few engineer participants completed the survey $(N=6)$. In the next data collection phase, more participants will complete the survey and we will have a better chance to examine the relations between engineers and students.

\section{Acknowledgement}

This material is supported by the National Science Foundation under EEC Grant Numbers 1129403 and 1129411. Any opinions, findings, conclusions, or recommendations presented are those of the authors and do not necessarily reflect the views of the National Science Foundation.

\section{References}

[1] Field, D.A., (2004). Education and training for cad in the auto industry. Computer-Aided Design, 36 (14), 1431-1437.

[2] Hamade, R.F., Artail, H.A. \& Jaber, M.Y., (2007). Evaluating the learning process of mechanical cad students. Computers \& Education, 49 (3), 640-661.

[3] Ye, Z., Peng, W., Chen, Z. \& Cai, Y.-Y., (2004). Today's students, tomorrow's engineers: An industrial perspective on cad education. Computer-Aided Design, 36 (14), 1451-1460.

[4] Lang, G.T., Eberts, R.E., Gabel, M.G. \& Barash, M.M., (1991). Extracting and using procedural knowledge in a cad task. IEEE Transactions on Engineering Management, 38 (3), 257-268.

[5] Chester, I., (2007). Teaching for cad expertise. International Journal of Technology and Design Education, 17 (1), 23-35.

[6] Anderson, L.W., Krathwohl, D.R. \& Bloom, B.S., (2001). A taxonomy for learning, teaching, and assessing : A revision of bloom's taxonomy of educational objectives, Complete ed. New York: Longman. 
[7] Feltovich, P.J., Prietula, M.J. \& Ericsson, K.A., (2006). Studies of expertise from psychological perspectives. In Ericsson, K.A. ed. The cambridge handbook of expertise and expert performance. Cambridge ; New York: Cambridge University Press, xv, 901 p.

[8] Chi, M.T.H., (2006). Two approaches to the study of experts' characteristics. In Ericsson, K.A. ed. The cambridge handbook of expertise and expert performance. Cambridge ; New York: Cambridge University Press, xv, $901 \mathrm{p}$.

[9] Brand-Gruwel, S., Wopereis, I. \& Vermetten, Y., (2005). Information problem solving by experts and novices: Analysis of a complex cognitive skill. Computers in Human Behavior, 21 (3 SPEC. ISS.), 487-508.

[10] Atman, C.J., Adams, R.S., Cardella, M.E., Turns, J., Mosborg, S. \& Saleem, J., (2007). Engineering design processes: A comparison of students and expert practitioners. Journal of Engineering Education, 96 (4), 359-379.

[11] Morozov, A., Kilgore, D. \& Atman, C., (2007). Breadth in design problem scoping: Using insights from experts to investigate student processes. 114th Annual ASEE Conference and Exposition. Honolulu, HI.

[12] Ball, L.J., Ormerod, T.C. \& Morley, N.J., (2004). Spontaneous analogising in engineering design: A comparative analysis of experts and novices. Design Studies, 25 (5), 495-508.

[13] Kavakli, M. \& Gero, J.S., (2002). The structure of concurrent cognitive actions: A case study on novice and expert designers. Design Studies, 23 (1), 25-40.

[14] Bhavnani, S.K., James H. Garrett, J. \& Shaw, D.S., (1993). Leading indicators of cad experience. Proceedings of the fifth international conference on Computer-aided architectural design futures. Pittsburgh, Pennsylvania, United States: North-Holland Publishing Co., 313334.

[15] Hartman, N.W., (2005). Defining expertise in the use of constraint-based cad tools by examining practicing professionals. Engineering Design Graphics Journal, 69 (1), 6-15.

[16] Rynne, A. \& Gaughran, W., (2008). Cognitive modeling strategies for optimum design intent in parametric modeling. Computers in Education Journal, 18 (1), 55-68.

[17] Hadim, H.A. \& Esche, S.K., (2002). Enhancing the engineering curriculum through projectbased learning. Frontiers in Education, 2002. FIE 2002. 32nd Annual. F3F-1-F3F-6 vol.2.

[18] Harris, M. \& Cullen, R., (2009). A model for curricular revision: The case of engineering. Innovative Higher Education, 34 (1), 51-63.

[19] Mckenna, A.F., (2007). An investigation of adaptive expertise and transfer of design process knowledge. Journal of Mechanical Design, 129 (7), 730-734.

[20] Hatano, G. \& Inagaki, K., (1986). Two courses of expertise. In Stevenson, H.W., Azuma, H. \& Hakuta, K. eds. Child development and education in japan. New York: W.H. Freeman, 262272.

[21] Schwartz, D.L., Bransford, J.D. \& Sears, D., (2005). Efficiency and innovation in transfer. In Mestre, J.P. ed. Transfer of learning from a modern multidisciplinary perspective. Greenwich, CT :: IAP.

[22] Hatano, G. \& Oura, Y., (2003). Commentary: Reconceptualizing school learning using insight from expertise research. Educational Researcher, 32 (8), 26-29.

[23] Fisher, F.T. \& Peterson, P.L., (2001). A tool to measure adaptive expertise in biomedical engineering students. 2001 ASEE Annual Conference and Exposition:. Albuquerque, NM: ASEE, 1249-1263.

[24] Kaiser, H.F., (1960). The application of electronic computers to factor analysis Educational and Psychological Measurement 20 (1), 141-151. 
[25] Cattell, R.B., (1966). The scree test for the number of factors. Multivariate Behavioral Research, 1 (2), 245-276.

[26] Hair, J.F. \& Anderson, R.E., (2010). Multivariate data analysis: Prentice Hall.

[27] Costello, A.B. \& Osborne, J.W., (2005). Best practices in exploratory factor analysis: Four recommendations for getting the most from your analysis. Practical Assessment, Research \& Evaluation, 10 (7), 1-9.

[28] Reise, S.P., Waller, N.G. \& Comrey, A.L., (2000). Factor analysis and scale revision. Psychological Assessment, 12 (3), 287-297. 


\section{Appendix}

\section{Adaptive Expertise Related to Computer Aided Design (CAD) \\ Student Survey Form}

(Some demographic questions were different in the engineering survey and in the student survey administered at one of the two campuses).

Thank you for participating in this study.

This survey includes two sections. Section I asks for your demographic information. Section II includes some opinion and attitude questions towards the characteristics of adaptive expertise. Section II items are to explore your personal views and experiences. Your responses to this survey will remain confidential and will not be shared with anyone other than the researchers.

\section{Section I: Demographic Questionnaire}

Please answer the below questions by checking the appropriate boxes or filling in the necessary field:

\begin{tabular}{|c|c|c|c|c|c|}
\hline 1 & Name - Last Name (write in) & & & & \\
\hline 2 & Sex (check) & Male & Female & & \\
\hline 3 & Age (write in) & & & & \\
\hline 4 & Rank/ level in college (check) & Freshman & Sophomore & Junior & Senior \\
\hline 5 & Major (write in) & & & & \\
\hline 6 & $\begin{array}{l}\text { Have you had a professional work } \\
\text { experience related to engineering } \\
\text { (e.g., internship, co-op, etc.)? }\end{array}$ & Yes & No & & \\
\hline 7 & $\begin{array}{l}\text { Have you had any technical } \\
\text { employment and research } \\
\text { experience related to engineering } \\
\text { (e.g., machines shops, labs, } \\
\text { project tasks, etc.) }\end{array}$ & Yes & No & & \\
\hline
\end{tabular}

\section{Please go to next page for survey questions}


Section II: Adaptive Expertise Questionnaire (Fisher and Peterson, 2001)

In this section, please read each item carefully and indicate your position by circling one of the numbers in the 6 point scale as 1 (strongly disagree), 2 (disagree), 3 (slightly disagree), 4 (slightly agree), 5 (agree), and 6 (strongly agree). Note that number 6 on the right designates the highest agreement and number 1 on the left designates the lowest agreement with the item.

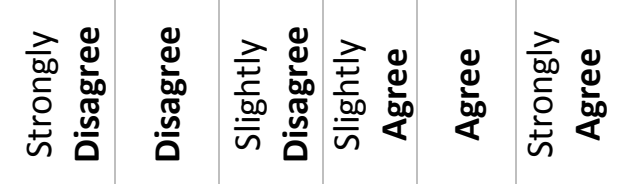

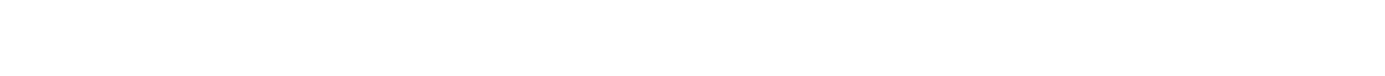

1. I create several models of an engineering problem to see which one I like best.

\begin{tabular}{l|l|l|l|l|l|}
1 & 2 & 3 & 4 & 5 & 6 \\
\hline
\end{tabular}

2. As I learn, I question my understanding of the new information.

$\begin{array}{llllll}1 & 2 & 3 & 4 & 5 & 6\end{array}$

3. I feel uncomfortable when I cannot solve difficult problems.

\begin{tabular}{l|l|l|l|l|l}
1 & 2 & 3 & 4 & 5 & 6
\end{tabular}

4. Knowledge that exists today may be replaced with a new understanding tomorrow

5. Usually there is one correct method in which to represent a problem.

6. I often try to monitor my understanding of the problem.

$\begin{array}{llllll}1 & 2 & 3 & 4 & 5 & 6\end{array}$

7. I am afraid to try tasks that I do not think I will do well.

8. Most knowledge that exists in the world today will not change.

\begin{tabular}{l|l|l|l|l|l}
1 & 2 & 3 & 4 & 5 & 6
\end{tabular}

9. When I consider a problem, I like to see how many different ways I can look at it.

$\begin{array}{llllll}1 & 2 & 3 & 4 & 5 & 6\end{array}$

10. As a student, I cannot evaluate my own understanding of new material.

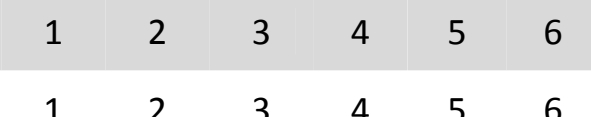

11. Although I hate to admit it, I would rather do well in a class than learn a lot.

12. Scientists are always revising their view of the world around them.

$\begin{array}{llllll}1 & 2 & 3 & 4 & 5 & 6\end{array}$

13. I tend to focus on a particular model in which to solve a problem.

14. I rarely monitor my own understanding while learning something new.

\begin{tabular}{l|l|l|l|l|l}
1 & 2 & 3 & 4 & 5 & 6
\end{tabular}

15. One can increase their level of expertise in any area if they are willing to try.

16. Facts that are taught to me in class must be true.

17. I am open to changing my mind when confronted with an alternative viewpoint.

18. When I know the material, I can recognize areas where my understanding is incomplete

19. Expertise can be developed through hard work.

20. Existing knowledge in the world seldom changes.

21. I rarely consider other ideas after I have found the best answer.

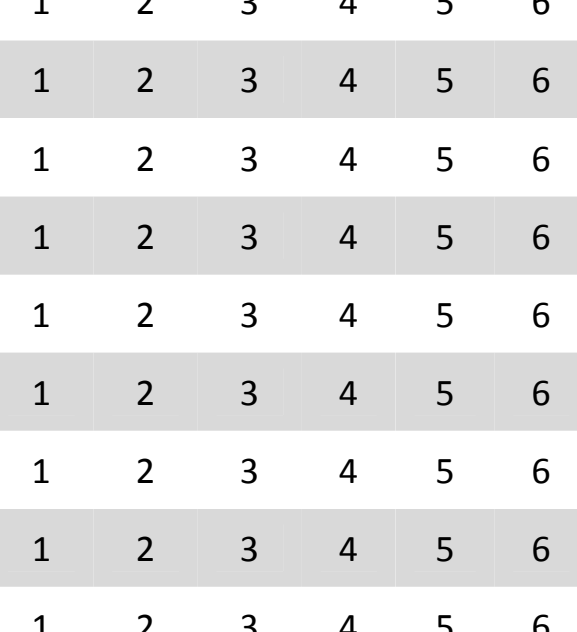

$\begin{array}{llllll}1 & 2 & 3 & 4 & 5 & 6\end{array}$

\begin{tabular}{l|l|l|l|l|l}
1 & 2 & 3 & 4 & 5 & 6
\end{tabular}

\begin{tabular}{|c|c|c|c|c|c|}
\hline 1 & 2 & 3 & 4 & 5 & 6 \\
\hline 1 & 2 & 3 & 4 & 5 & 6 \\
\hline 1 & 2 & 3 & 4 & 5 & 6 \\
\hline
\end{tabular}


22. I have difficulty in determining how well I understand a topic.

23. To become an expert in engineering, you must have an innate talent for engineering.

24. Challenge stimulates me.

25. I find additional ideas burdensome after I have found a way to solve the problem.

26. I monitor my performance on a task.

27. Experts in engineering are born with a natural talent for their field.

28. Scientific theory slowly develops as ideas are analyzed and debated.

29. For a new situation, I consider a variety of approaches until one emerges superior.

30. As I work, I ask myself how I am doing and seek out appropriate feedback.

31. Experts are born, not made.

32. Even if frustrated when working on a difficult problem, I can push on.

33. Scientific knowledge is developed by a community of researchers.

34. I solve all related problems in the same manner.

35. Poorly completing a project is not a sign of a lack of intelligence.

36. When I solve a new problem, I always try to use the same approach.

37. Scientific knowledge is discovered by individuals.

38. When I struggle, I wonder if I have the intelligence to succeed in engineering.

39. There is one best way to approach a problem.

40. I seldom evaluate my performance on a task.

41. I feel uncomfortable when unsure if I am doing a problem the right way.

42. Progress in science is due mainly to the work of sole individuals.

Thank you for your time

Please return the form to the researchers.

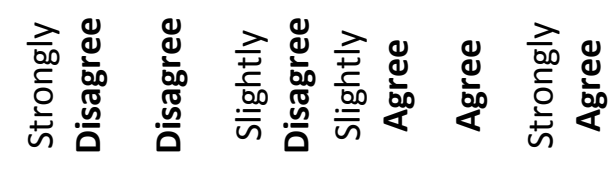

\begin{tabular}{|l|l|l|l|l|l|}
$\mathbf{1}$ & $\mathbf{2}$ & $\mathbf{3}$ & $\mathbf{4}$ & $\mathbf{5}$ & $\mathbf{6}$ \\
\hline 1 & 2 & 3 & 4 & 5 & 6 \\
\hline 1 & 2 & 3 & 4 & 5 & 6
\end{tabular}

\begin{tabular}{l|l|l|l|l|l}
1 & 2 & 3 & 4 & 5 & 6
\end{tabular}

$\begin{array}{llllll}1 & 2 & 3 & 4 & 5 & 6\end{array}$

\begin{tabular}{|l|l|l|l|l|l|}
\hline 1 & 2 & 3 & 4 & 5 & 6 \\
\hline 1 & 2 & 3 & 4 & 5 & 6 \\
\hline 1 & 2 & 3 & 4 & 5 & 6 \\
\hline
\end{tabular}

$\begin{array}{llllll}1 & 2 & 3 & 4 & 5 & 6\end{array}$

\begin{tabular}{l|l|l|l|l|l}
1 & 2 & 3 & 4 & 5 & 6
\end{tabular}

\begin{tabular}{|c|c|c|c|c|c|}
\hline 1 & 2 & 3 & 4 & 5 & 6 \\
\hline 1 & 2 & 3 & 4 & 5 & 6 \\
\hline
\end{tabular}

$\begin{array}{llllll}1 & 2 & 3 & 4 & 5 & 6\end{array}$

\begin{tabular}{l|l|l|l|l|l}
1 & 2 & 3 & 4 & 5 & 6
\end{tabular}

$\begin{array}{llllll}1 & 2 & 3 & 4 & 5 & 6\end{array}$

\begin{tabular}{l|l|l|l|l|l}
1 & 2 & 3 & 4 & 5 & 6
\end{tabular}

$\begin{array}{llllll}1 & 2 & 3 & 4 & 5 & 6\end{array}$

\begin{tabular}{l|l|l|l|l|l}
1 & 2 & 3 & 4 & 5 & 6
\end{tabular}

$\begin{array}{llllll}1 & 2 & 3 & 4 & 5 & 6\end{array}$

\begin{tabular}{l|l|l|l|l|l}
1 & 2 & 3 & 4 & 5 & 6
\end{tabular}

$\begin{array}{llllll}1 & 2 & 3 & 4 & 5 & 6\end{array}$

\begin{tabular}{l|l|l|l|l|l}
1 & 2 & 3 & 4 & 5 & 6
\end{tabular}

